\title{
Estimating the concentration of viral pathogens and indicator organisms in the final effluent of wastewater treatment processes using stochastic modelling
}

\author{
Edgard Dias ${ }^{1,2}$, James Ebdon ${ }^{2}$ and Huw Taylor ${ }^{2}$ \\ ${ }^{1}$ Department of Sanitary and Environmental Engineering, Faculty of Engineering, Federal \\ University of Juiz de Fora, Juiz de Fora / MG, Brazil, 36.036-330 \\ ${ }^{2}$ The Environment and Public Health Research Group (EPHReG), School of Environment and \\ Technology, University of Brighton, Brighton, UK, BN2 4GJ \\ edgard.dias@ufjf.edu.br, je3@brighton.ac.uk,h.d.taylor@brighton.ac.uk
}

\section{Abstract}

The presence of waterborne microbial (including viral) pathogens, in wastewater poses a potential risk to human health when wastewaters are reused either directly or indirectly. Therefore, reuse activities need to be regulated in such a way as to protect human health and to this end, quantitative microbial risk assessment (QMRA) has been successfully used to formulate evidencebased reuse regulations. The QMRA approach depends, however, on reliable information about the various elements of the system, including the wastewater treatment component. One point of major concern is the determination of pathogen concentrations, especially viral pathogens, in treated wastewater, as a consequence of their low levels and problems associated with the detection limit of enumeration methods. Therefore, the research described here aimed to develop stochastic simulations from empirical data to estimate likely concentrations of specified enteric microorganisms in final effluents of municipal wastewater treatment plants based on either activated sludge (AS) or trickling filter (TF) as the secondary biological treatment stage and thereby support the construction of functional QMRA models. Wastewater samples were collected every fortnight, during a twelve-month period, at each stage of four full-scale wastewater treatment plants 
(WWTP) in southern England (two AS and two TF plants) ( $\mathrm{n}=360$ samples) in order to build a robust dataset. Probability density functions (PDF) were then fitted to empirical data and used as input variables in the proposed model, which considered the concentration of the assessed microorganisms in the raw wastewater and the removal rates in primary, secondary and tertiary treatment stages. Final concentrations of pathogenic and indicator organisms were then estimated using stochastic simulations. The proposed stochastic model was able to predict both accurately and reliably the likely concentration of microorganisms in the final effluent of both systems. Moreover, sensitivity analysis revealed that the concentrations of the microorganisms in raw wastewater and their removal rates in the secondary treatment stages had the greatest influence on the predictive output. It was therefore concluded that, provided due attention is paid to the quality of the specific input variables of the model, stochastic modelling may represent a valuable tool to support integrated water and sanitation safety planning approaches to human health risk management of wastewater reuse systems, based on the use of QMRA models. The approach may also support better design and operation of wastewater treatment processes so as to maximise pathogen removal in support of Sustainable Development Goal 6 Target 3 of the United Nations.

Key words: QMRA, human adenovirus, phages, faecal indicator bacteria, wastewater reuse, sanitation safety planning.

\section{INTRODUCTION}

Evolving climate change scenarios and growing water demand for various water-related activities in recent years have increased the pressure for treated wastewater to be reused in many parts of the world. In practice, all wastewater is 'reused', though not necessarily directly. Examples of direct reuse include agricultural irrigation, aquaculture, and various domestic (e.g., toilet flushing) and industrial activities. However, when treated (or untreated) wastewater is discharged directly to river catchments, it is indirectly reused (de facto reuse), in that the downstream water body is often used 
for recreational activities, including fishing, swimming and kayaking, agriculture and even for drinking water abstraction. Increasingly, treated wastewater is being intentionally treated to drinking water quality, a practice referred to as direct potable reuse (DPR) (Warsinger et al., 2018).

Although wastewater reuse presents numerous potential environmental and economic benefits (Anderson, 2003; Garcia and Pargament, 2015; Akhoundi and Nazif, 2018), a matter of considerable societal concern is the potential risk to public health associated with human contact with waterborne pathogenic microorganisms present in the wastewater $\mathrm{WHO}, 2006$; Beaudequin et al., 2015). More specifically, growing evidence suggests that waterborne viral pathogens are inadequately removed from existing wastewater treatment systems (Malamis et al., 2015) and that bacterial indicators used to assess water quality fail to detect their presence accurately (USEPA, 2015). Numerous outbreaks of human infectious disease have been associated with contact with waters contaminated with enteric viruses, such as rotaviruses (Parashar et al., 2006; Fumian et al., 2011; WHO, 2011; Xue et al., 2013), noroviruses (Victoria et al., 2010; Sima et al., 2011; WHO, 2011) and human adenoviruses (Kuo et al., 2010; Sidhu, Ahmed and Toze, 2013).

The lack of standards and/or regulations remains a limiting factor for wastewater reuse in many countries. It is important, therefore, to consider the development, adoption and continuous updating of appropriate, evidence-based regulations to protect human health and sustainable development. One example of this approach is the use of quantitative microbial risk assessment (QMRA), which considers an acceptable risk and multiple health protection measures. The QMRA approach has been applied by different researchers evaluating human health risks associated with drinking water (Blokker, Smeets and Medema, 2014; Razzolini et al., 2016), wastewater reuse (Soller et al., 2017; Soller, Eftim and Nappier, 2018) and land application of biosolids (Gale, 2005; Eisenberg et al., 2008; Gerba et al., 2008). The QMRA approach has also already been successfully used to support the formulation of regulations associated with drinking water quality (WHO, 2011; USEPA, 2012) and the reuse of wastewater in agriculture (NRMMC/EPHC/AHMC, 2006; WHO, 2006). 
The QMRA approach depends, however, on reliable information about the input variables considered in its mathematical models. QMRA models may be either deterministic or stochastic. Deterministic (single output) models are characterised by input models that are expressed by single estimates, which are normally measures of central tendency (e.g., median, arithmetic mean, geometric mean). However, stochastic models differ in that they are given value ranges according to a specific frequency or probability distribution function (PDF), therefore incorporating uncertainties around the input parameters of the model and, consequently, the output variable (Morgan and Henrion, 1990; Vose, 2008). Additionally, stochastic modelling allows the propagation of uncertainties by successive and random sampling of each variable, e.g., by the use of Monte Carlo sampling or Latin Hypercube sampling, both based on the cumulative distribution function (CDF) of the input variables (Vose, 2008; PALISADE, 2013).

In parallel with stochastic modelling, the use of sensitivity analysis allows the input variables of the model that have the highest impact on the output variable to be identified (Vose, 2008). With this information, it is possible to choose which input variable should be given more attention when building the exposure model (Zwieterin and van Gerwen, 2000; Christopher Frey and Patil, 2002; PALISADE, 2013).

The aim of this study was to develop stochastic simulations, using empirical data and a simple mathematical model, to achieve a probabilistic estimation of the concentration of viral pathogens, faecal indicator bacteria (FIB) and bacteriophages in final effluents of two widely-used wastewater treatment technologies, namely the activated sludge (AS) and trickling filter (TF) processes, as the basis for a risk management approach to sustainable wastewater management and reuse.

\section{MATERIAL \& METHODS}

\subsection{Empirical data gathering}

Four wastewater treatment plants (WWTP) were used to construct a comprehensive dataset of parameters to describe treatment operation and efficacy. The four WWTP were located in southern 
England, UK, and included secondary biological treatment, in the form of activated sludge (AS) followed by sand filters as tertiary treatment, and trickling filters (TF) followed by sedimentation ponds as tertiary treatment. The scale of the monitored WWTP ranged from 'small' $(5,000$ p.e.) to 'medium' (45,000 p.e.). Samples were collected every fortnight, from June 2013 to May 2014 (inc.), which resulted in a total of 24 sampling occasions. On each sampling occasion, four samples were collected at each WWTP: (i) raw wastewater (RW); (ii) primary effluent, immediately after the primary sedimentation tanks (PST); (iii) secondary effluent, immediately after the secondary sedimentation tanks (SST); and (iv) final effluent, after the tertiary treatment systems (FE).

\subsection{Enumeration of indicator organisms}

Presumptive counts of faecal coliforms (FE) and intestinal enterococci (IE) were made following the protocols described in ISO 9308-1:2000 (BSI, 2009) and ISO 7899-2:2000 (BSI, 2000), respectively. For both bacterial groups, samples were filtered through $0.45 \mu \mathrm{m}$ cellulose nitrate membrane filters (Sartorius, Göttingen, Germany) and then incubated on selective agar at specific temperatures: membrane incubation on M-FC agar (Merck Millipore, Darmstadt, Germany) at $44 \pm 2^{\circ} \mathrm{C}$ for $24 \pm 2 \mathrm{~h}$ for faecal coliforms; and on Slanetz and Bartley agar (Merck Millipore, Darmstadt, Germany) at $37 \pm 2^{\circ} \mathrm{C}$ for $44 \pm 2 \mathrm{~h}$ for intestinal enterococci. Concentrations of FIB were expressed as colony-forming units per $100 \mathrm{~mL}\left(\mathrm{cfu} .100 \mathrm{~mL}^{-1}\right)$. Phages were detected and enumerated as follows: somatic coliphages (SOMPH) were enumerated according to ISO 107052:2001 (BSI, 2001a) using the host strain E. coli WG-5; F-RNA coliphages (F-RNAPH) were enumerated according to 10705-1:2001 (BSI, 2002) using the host strain S. typhimurium WG-49; and phages infecting $B$. fragilis (Bf124PH) were enumerated according to ISO 10705-4:2001 (BSI, 2001b) using the host strain B. fragilis GB-124. In order to increase sensitivity, the method was modified to process $5 \mathrm{~mL}$ rather than $1 \mathrm{~mL}$ of the sample, as described by (Vijayavel et al., 2010), to analyse the secondary effluent (SST) and final effluent (FE) of AS systems on the final twelve sampling dates. Concentrations of phages were expressed as plaque-forming units per $100 \mathrm{~mL}$ (pfu.100mL ${ }^{-1}$ ). 


\subsection{Enumeration of enteric viruses (molecular analysis)}

Two viral pathogens were enumerated in the wastewater samples analysed: norovirus (Nv); and human adenovirus (HAdv). Once samples had been collected and transferred to the laboratory, a 10-mL volume of each sample, with $5 \%$ glycerol $(\mathrm{v} / \mathrm{v})$ added, was stored at $-20^{\circ} \mathrm{C}$ until processed. In order to increase the sensitivity of the method, this volume was increased to $50 \mathrm{~mL}$, with $5 \%$ glycerol (v/v) added, for samples of secondary (SST) and final (FE) effluent from both AS and TF systems for the final 16 sampling occasions. Samples were allowed to thaw at $4^{\circ} \mathrm{C}$. The $10 \mathrm{~mL}$ samples were transferred to $50-\mathrm{mL}$ sterile polypropylene centrifuge tubes (Fisherbrand, Loughborough, UK) and viruses were eluted using $2.5 \mathrm{~mL}$ of glycine buffer $2.0 \mathrm{M}, \mathrm{pH} 9.5$ (1:0.25, $\mathrm{v} / \mathrm{v}$ ). The $50 \mathrm{~mL}$ samples were transferred to $100-\mathrm{mL}$ sterile polyethylene containers (Plastiques Gosselin, Borre, France) and the viruses were eluted using $12.5 \mathrm{~mL}$ of glycine buffer $2.0 \mathrm{M}, \mathrm{pH} 9.5$ $(1: 0.25, \mathrm{v} / \mathrm{v})$. Samples were stirred rapidly in an orbital shaker for $30 \mathrm{~min}$ at $300 \mathrm{rpm}$ and then filtered through $0.22 \mu \mathrm{m}$ polyethersulfone Millex-GP syringe filter units (Merck Millipore, Darmstadt, Germany) in order to remove bacteria and other suspended material. Subsequently, samples were concentrated using Amicon Ultra-15 centrifugal filters units (50 kDa molecular weight cut-off) (Merck Millipore, Darmstadt, Germany) and centrifuged at $5,000 \mathrm{~g}$ at $4^{\circ} \mathrm{C}$ for 10 min to obtain a final volume of less than $500 \mu \mathrm{L}$. Multiple centrifugation steps were applied to the $50-\mathrm{mL}$ samples. The final volume was made up to $500 \mu \mathrm{L}$ with phosphate buffer solution (PBS) and stored at $4^{\circ} \mathrm{C}$ before nucleic acids were extracted. The preparation methods used were tested for their recovery of $\mathrm{SOMPH}$, and a recovery rate of $21 \%$ was recorded. This recovery rate was then used to calculate the concentrations of $\mathrm{Nv}$ and HAdv. After the preparation steps, viral DNA and RNA were extracted from samples using the commercial kits QIAamp Fast DNA Stool Mini Kit and QIAamp Viral RNA Mini Kit (Qiagen, Hilden, Germany), respectively, according to the manufacturers' instructions. Both DNA and RNA extracts were then stored at $-80^{\circ} \mathrm{C}$ until further processing within six months. 
Prior to RT-qPCR assay, samples were allowed to thaw at $4^{\circ} \mathrm{C}$. All qPCR assays were performed using a Qiagen Rotor-gene Q (Qiagen, Hilden, Germany). 'Positive', 'no template' and 'internal extraction' controls were used in every assay run. HAdv RT-qPCR was carried out by amplifying the hexon gene using the commercial primer and probe set Adenovirus Type F and $G$ genesig® Advanced Kit (PrimerDesign, Southampton, UK), according to the manufacturer's instructions. Nv G1 RT-qPCR was carried out by amplifying the Norovirus GI capsid protein gene, whereas Nv G2 RT-qPCR was carried out by amplifying Norovirus GII RNA dependent RNA polymerase gene, both using the commercial primer and probe set Norovirus Genogroups 1 and 2 genesig® Advanced Kit (PrimerDesign, Southampton, UK), according to the manufacturer's instructions. Primers and probes for both HAdv and Nv qPCR assays were designed by the manufacturer (PrimerDesign, Southampton, UK). The primers present $100 \%$ homology with all reference sequences included in the $\mathrm{NCBI}$ database and therefore these kits are considered to have very broad detection profiles. For HAdv, each sample $(5 \mu \mathrm{L})$ was prepared with a $15 \mu \mathrm{L}$ reaction mix, containing $10 \mu \mathrm{L}$ PrecisionPLUS ${ }^{\mathrm{TM}}$ 2x qPCR MasterMix, $1 \mu \mathrm{L}$ Adv F+G primer/probe mix, $1 \mu \mathrm{L}$ internal extraction control primer/probe mix and $3 \mu \mathrm{L}$ RNAse/DNAse free water. For Nv G1 and G2 detection, each sample $(5 \mu \mathrm{L})$ was prepared with a $15 \mu \mathrm{L}$ reaction mix, containing $10 \mu \mathrm{L}$ PrecisionTM OneStep 2x qRT-PCR MasterMix, $1 \mu \mathrm{L}$ RNA-pol primer/probe mix, $1 \mu \mathrm{L}$ internal extraction control primer/probe mix and $3 \mu \mathrm{L}$ RNAse/DNAse free water. Thermal conditions for HAdv consisted of enzyme activation for $2 \min$ at $95^{\circ} \mathrm{C}$, followed by 50 cycles of denaturation for $10 \mathrm{~s}$ at $95^{\circ} \mathrm{C}$ and data collection for $60 \mathrm{~s}$ at $60^{\circ} \mathrm{C}$. Nv detection followed the same thermal conditions, with the addition of a prior reverse transcription stage of $10 \mathrm{~min}$ at $42^{\circ} \mathrm{C}$ before enzyme activation. No inhibition control was performed. Concentrations of viral pathogens were expressed as copies per $100 \mathrm{~mL}$ (copies. $100 \mathrm{~mL}^{-1}$ ).

The preparation (elution and concentration) methods as well as the RT-qPCR technique applied in this study are further explained in details in (Dias, 2016) and (Dias, Ebdon and Taylor, 2018). Nondetects were not included in the statistical analyses performed in this study for a series of reasons as described in (Dias, Ebdon and Taylor, 2018). 


\subsection{Stochastic modelling}

For the stochastic modelling, the data obtained from the four WWTP were divided into two groups: one group comprising the data collected from the two TF plants; and a second group comprising the data collected from the two AS plants. Before this, the datasets for each organism, which were obtained from each of the two AS treatment plants, were compared with one another. The same was done for the datasets obtained from each of the two TF treatment plants. This involved the application of the ranked t-test at a significance level of $5 \%(\alpha=0.05)$. Although on occasion significant differences between the data obtained from the two AS systems were found and also data obtained from the two TF systems, this was not normally the case. These results therefore justify the decision to group together the two datasets from each treatment type (either AS or TF) for all subsequent analyses.

The proposed stochastic model is presented in Eq. 1 and 2. Similar models have been applied to water (Smeets, 2011) and other wastewater treatment systems (Haas and Trussell, 1998; Olivieri et al., 1999; Soller et al., 2017). According to this model, the concentrations of the various microorganisms in the final effluent $\left(C_{\text {final }}\right)$ were calculated from their concentrations in the raw wastewater $\left(\mathrm{C}_{\text {raw }}\right)$ and their removal rates at each step of the treatment process $\left(\pi_{d}\right)$, as described in Eq. 1 and 2.

Eq. 1

Where: $\mathrm{C}_{\text {final }}=$ microorganism concentration in final effluent; $\mathrm{C}_{\text {raw }}=$ microorganism concentration in raw wastewater; $\pi_{\text {prim }}=$ efficacy of preliminary and primary treatment; $\pi_{\mathrm{sec}}$ $=$ efficacy of secondary treatment; $\pi_{\text {tert }}=$ efficacy of tertiary treatment.

Eq. 2 
Where: $\Pi_{d}=$ efficacy of the treatment $d ; \mathrm{C}_{\mathrm{d} . \text { out }}=$ microorganism concentration after treatment $d ; \mathbf{C}_{\text {d.in }}=$ microorganism concentration before treatment $d$.

Data from raw wastewater samples were used for the $C_{\text {raw }}$ component of the model (Eq. 1). In order to calculate the efficacy of each treatment stage $\left(\pi_{d}\right)$, two different datasets were used as follows: raw wastewater (RW) and primary sedimentation tank (PST) datasets were used to calculate the $\Pi_{p r i m}$ factor; PST and secondary sedimentation tank (SST) datasets were used to calculate the $\pi_{\text {sec }}$ factor; and SST and final effluent (FE) datasets were used to calculate the $\pi_{\text {tert }}$ factor. In theory, the concentration of microorganisms in the inlet would be expected to be higher than the concentration in the outlet of all treatment steps. Consequently, the values of $\Pi_{\text {prim }}, \Pi_{\mathrm{sec}}$ and $\pi_{\text {tert }}$ should range from 0 to $1\left(\pi_{d}=C_{\text {d.out }} / C_{\text {d.in }}\right.$; Eq. 2). However, the opposite can happen, in which case values of $\pi_{\text {prim }}, \Pi_{\text {sec }}$ and $\pi_{\text {tert }}$ greater than 1 may arise. Therefore, in order to overcome this issue, whenever levels of microorganisms in the outlet exceeded those in the inlet, the value of $\Pi_{d}$ was assumed to be equal to one.

Probability density functions (PDF) were fitted to the $C_{r a w}, \Pi_{p r i m}, \Pi_{s e c}$ and $\pi_{\text {tert }}$ dataset. For all PDF $\left(C_{\text {raw }}, \Pi_{\text {prim }}, \Pi_{\text {sec }}\right.$ and $\left.\Pi_{\text {tert }}\right)$ the lower bound limit was fixed as zero. Data fitting to the raw data at each treatment step was not conducted as it would have involved the use of models (e.g., plug-

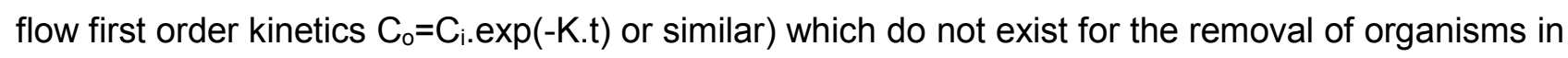
AS and TF systems. The authors therefore opted for a simplified model $\left(C_{\text {final }}=C_{\text {raw }} \times \pi_{\text {prim }} \times \pi_{\text {sec }} \times \pi_{\text {tert }}\right)$, which instead uses secondary data $\left(\pi_{\text {prim }}, \Pi_{\text {sec }}\right.$ and $\left.\Pi_{\text {tert }}\right)$ calculated from primary data (RW, PST, SST, FE). Here, the Anderson-Darling (A-D) 'goodness-of-fit' statistic was performed using the statistical software @Risk, version 6.3.1 (Palisade Corporation, Ithaca, USA), which calculates the value of the A-D test for different theoretical distributions. Whether or not a particular PDF was chosen depended on the value of the A-D test and the probabilityprobability (P-P) 'goodness-of-fit' plots generated. The concentrations in the final effluents were then estimated using the proposed model (Eq. 1) by stochastic simulation with Latin Hypercube sampling and 10,000 iterations, again using the software @Risk, version 6.3.1. With regard to the 
model input factors, PDF were fitted to the outputs obtained from simulations, again using A-D test and P-P plots with the aid of the software @Risk, version 6.3.1.

In order to validate the proposed model, the estimated concentrations of the different microorganisms were compared statistically with the observed concentrations obtained from the WWTP monitoring programme (non-normal distribution datasets), in terms of median values, using the non-parametric Mann-Whitney test at a significance level of $5 \%(\alpha=0.05)$.

\subsection{Sensitivity analysis}

Sensitivity analysis tests were performed to verify the impact of each input variable of the proposed model on the output. Sensitivity analysis is based on the concept of setting fixed values to a given input variable, and then running simulations with the various alternatives, one at a time, in order to evaluate how the values of the output variable change as a result. This process is undertaken using all the input variables of the model. The impact of the input variables on the output is then evaluated by assessing the amplitude of the range of mean values of the estimates obtained in each simulation performed. As all input variables $\left(C_{\text {raw }}=\right.$ microorganism concentration in raw wastewater; $\pi_{p r i m}=$ efficacy of preliminary and primary treatment; $\pi_{s e c}=$ efficacy of secondary treatment; $\Pi_{\text {tert }}=$ efficacy of tertiary treatment) of this study are given as probability distributions, it was decided to set specific fixed percentiles $(1,5,25,50,75,95$ and $99 \%)$ of such distributions and then calculate the impact on the outputs $\left(C_{\text {final }}=\right.$ microorganism concentration in final effluent $)$ in the iterations associated with each percentile of each input variable of the model. As a result of the sensitivity analysis tests undertaken, 'tornado graphs', which are graphics that display a ranking of the input variables that impact the output mean value (from lowest (at bottom of the graph) to greatest (at the top of the graph)), were obtained.

\section{RESULTS}

\subsection{Monitoring Results}


Figure 1 presents boxplot graphics of the concentrations of somatic coliphages (SOMPH), F-RNA coliphages (F-RNAPH), phages infecting $B$. fragilis $(\mathrm{Bf} 124 \mathrm{PH})$, faecal coliforms $(\mathrm{FC})$, intestinal enterococci (IE), human adenovirus (HAdv), norovirus genogroup 1 ( Nv G1) and norovirus genogroup 2 (Nv G2), in RW, PST SST and FE samples from AS and TF systems. Further discussion on the monitoring results can be found in (Dias, 2016) and (Dias, Ebdon and Taylor, 2018).

In terms of mean concentrations in raw wastewater samples from both AS and TF systems, the concentration of FC (6.6-6.7 $\left.\log _{10} \mathrm{cfu} .100 \mathrm{~mL}^{-1}\right)$ was significantly higher than the levels of IE (5.8 $\log _{10}$ cfu. $\left.100 \mathrm{~mL}^{-1}\right)$ and SOMPH (5.9-6.1 $\log _{10}$ pfu. $\left.100 \mathrm{~mL}^{-1}\right)$, followed by HAdv (4.4-4.5 $\log _{10}$ copies. $\left.100 \mathrm{~mL}^{-1}\right)$, and then F-RNAPH and Bf124PH (3.2-3.3 and 3.5-3.8 $\log _{10}$ pfu.100mL-1, respectively) (ANOVA on ranks; $p$-value < 0.0001). Similar concentrations in municipal wastewater are reported in the literature for FIB (Kay et al., 2008; Carducci et al., 2009; De Luca et al., 2013; Purnell et al., 2015) and phages (Ebdon, Muniesa and Taylor, 2007; Aw and Gin, 2010). On the other hand, the levels of phages observed here in RW samples were lower than those reported by (De Luca et al., 2013) and (Purnell et al., 2015). The concentrations of HAdv observed here in raw wastewater were similar to those reported in some other studies (Aw and Gin, 2010; Hewitt et al., 2011), but were lower than the levels reported by others (Carducci et al., 2009; Kuo et al., 2010; Wolf, Hewitt and Greening, 2010; Hewitt et al., 2013; Sidhu, Ahmed and Toze, 2013). Concentrations of Nv G1 and Nv G2 were similar to other studies (Hewitt et al., 2011; Flannery et al., 2012; Eftim et al., 2017). However, the overall detection rate of Nv G1 and Nv G2 was very low, below $20 \%$ in all treatment steps in both AS and TF systems. Therefore, as a consequence of the low detection rate, discussion of the results for both Nv G1 and Nv G2 is necessarily limited. Low detection rates for $\mathrm{Nv}$ also justify why these micro-organisms were not considered in the stochastic modelling estimates in this study.

With regards to the removal rates observed in the WWTP monitored, although AS and TF systems are not designed with the main aim of removing pathogens, some reduction in the concentrations of viral pathogens and indicator organisms were observed through the systems. As expected, AS was shown to be significantly more effective at removing FIB and phages than TF (ranked t-test; 
$p$-value $<0.001$ for $\pi_{\text {global }}$ ). Considering the levels of microorganisms in AS (Error! Reference source not found.), similar concentrations of HAdv (Aw and Gin, 2010; Kuo et al., 2010; Hewitt et al., 2011), SOMPH (De Luca et al., 2013) and F-RNAPH (Aw and Gin, 2010) in AS secondary effluents have been reported in the literature. In contrast, higher concentrations of FIB (Kay et al., 2008; Flannery et al., 2012; De Luca et al., 2013) and F-RNAPH (Flannery et al., 2012) have been observed in some studies. Considerably lower concentrations of indicator organisms have been reported in MBR product (De Luca et al., 2013; Purnell et al., 2015). With regards to effluents of TF systems, similar levels of FIB and phages were reported by (Kay et al., 2008; Ebdon et al., 2012). 


\subsection{Results of stochastic simulation}

Before the stochastic modelling, probability distribution functions (PDF) were fitted to the data associated to each input variable of the model using the A-D test and P-P plot 'goodness-of-fitness' statistics and fixing the lower bound limit as zero. These are summarised in Table 1. It is evident that, in general, four different PDF seemed to describe the empirical data: log-normal, Weibull, Beta and Gamma. In only one case was a PDF other than these used: as a consequence of the small sample size of the input variable $\pi_{\text {tert }}$ for HAdv in AS systems, a point estimate value equal to one (i.e., no removal during the tertiary treatment) was considered.

Next, final concentrations of all microorganisms were estimated using the proposed model, considering the PDF described in Table 1, and using stochastic simulations with Latin Hypercube sampling and 10,000 iterations. Figure 2 presents the histograms, whereas Table 2 presents a summary of the statistics for the estimated concentrations of microorganisms in the final effluent of AS and TF systems.

The assumed conditions for the stochastic modelling exercise were shown to reflect the observed removal of phages, FIB and HAdv in AS and TF systems, as the proposed model appeared to estimate accurately the concentrations of all the studied microorganisms in the final effluents of both treatment systems. From the results of stochastic simulation presented in Figure 2 and Table 2 , it is notable that AS systems appeared to produce better quality final effluents (histograms shifted towards the left) than TF (histograms shifted towards the right) with regards to phages, FIB and HAdv (as observed from the monitoring programme; see Figure 1). AS final effluents recorded relatively low concentrations of F-RNAPH and $\mathrm{Bf} 124 \mathrm{PH}$, with mean estimated values equal to 1.40 and $1.52 \log _{10}$ pfu. $100 \mathrm{~mL}^{-1}$, respectively (Figure 1). The mean estimated concentrations of HAdv and IE in AS final effluents were equal to $2.69 \log _{10}$ copies. $100 \mathrm{~mL}^{-1}$ and $2.93 \log _{10} \mathrm{cfu} .100 \mathrm{~mL}^{-1}$, respectively, whereas average estimates of SOMPH and FC were considerably higher, at $3.55 \log _{10}$ pfu. $100 \mathrm{~mL}^{-1}$ and $3.41 \log _{10} \mathrm{cfu} .100 \mathrm{~mL}^{-1}$, respectively (Table 2). In TF systems, the mean estimated final concentrations were higher for all microorganisms than those estimated for AS effluents: the average estimated concentrations of F-RNAPH, Bf124PH, IE and HAdv were of the 
order of magnitude $3.0 \log _{10}\left(2.68 \log _{10}\right.$ pfu. $100 \mathrm{~mL}^{-1}, 2.94 \log _{10}$ pfu. $100 \mathrm{~mL}^{-1}, 3.41 \log _{10} \mathrm{cfu} .100 \mathrm{~mL}^{-1}$ and $3.46 \log _{10}$ copies. $100 \mathrm{~mL}^{-1}$, respectively), whereas the mean estimates of FC and SOMPH were $4.44 \log _{10} \mathrm{cfu} .100 \mathrm{~mL}^{-1}$ and $5.09 \log _{10} \mathrm{pfu} .100 \mathrm{~mL}^{-1}$, respectively (Table 2). Importantly, mean values of estimates were similar to the observed concentrations for all microorganisms in FE samples, from both AS and TF systems (Figure 1 and Table 2).

Considering the $95 \%$ confidence interval $(95 \% \mathrm{Cl})$, the estimated concentrations of phages in the final effluents of AS systems varied from 0.2 to $2.6 \log _{10}$ pfu. $100 \mathrm{~mL}^{-1}$ for F-RNAPH, from 0.3 to 2.7 $\log _{10}$ pfu. $100 \mathrm{~mL}^{-1}$ for $\mathrm{Bf} 124 \mathrm{PH}$, and from 2.5 to $4.6 \log _{10}$ pfu. $100 \mathrm{~mL}^{-1}$ for SOMPH (Table 2). Variations were higher for FIB and HAdv: from 2.0 to $4.9 \log _{10} \mathrm{cfu} .100 \mathrm{~mL}^{-1}$ for FC; from 1.2 to 4.7 $\log _{10}$ cfu. $100 \mathrm{~mL}^{-1}$ for IE; and from 0.8 to $4.6 \log _{10}$ copies. $100 \mathrm{~mL}^{-1}$ for HAdv (Table 2). In TF systems, variations observed in the $95 \% \mathrm{Cl}$ ranged from 3.9 to $6.3 \mathrm{pfu} .100 \mathrm{~mL}^{-1}$ for $\mathrm{SOPH}$, from 1.6 to $4.3 \log _{10}$ pfu. $100 \mathrm{~mL}^{-1}$ for $\mathrm{Bf} 124 \mathrm{PH}$, from 3.1 to $5.7 \mathrm{cfu} .100 \mathrm{~mL}^{-1}$ for $\mathrm{FC}$ and from $2.2-4.6 \log _{10}$ cfu. $100 \mathrm{~mL}^{-1}$ for IE; the variation for F-RNAPH was slightly higher (from 1.1 to $4.2 \log _{10} \mathrm{pfu} .100 \mathrm{~mL}^{-}$ ${ }^{1}$ ), and was considerably greater for HAdv (from 1.1 to $5.8 \log _{10}$ pfu. $100 \mathrm{~mL}^{-1}$ ) (Table 2).

In order to validate the proposed model, the estimated concentrations of the various microorganisms were statistically compared with the observed concentrations obtained from the WWTP monitoring programme. Here, the non-parametric Mann-Whitney test was used to compare the medians of estimated concentrations with observed concentrations at a significance level of $5 \%$ $(\alpha=0.05)$. Figures 3 and 4 present a graphical representation of descriptive statistics for the concentrations of the microorganisms in the final effluent of AS and TF systems obtained from the WWTP monitoring programme and stochastic modelling.

It can be seen in Figures 3 and 4 that the mean and median concentrations of the empirical data were very similar to those of simulated data for all microorganisms in both AS and TF systems. In general, the proposed model was shown to estimate accurately the concentrations of FIB, phages and HAdv in the final effluents of both AS and TF systems. In final effluent from AS systems, the median concentrations of empirical and simulated data were not shown to be significantly different (Mann Whitney test; $p$-value $\geq 0.05$ ) for any microorganisms other than F-RNAPH (median of 
simulated data lower than median of real data; $p$-value $=0.016$ ) and IE (median of simulated data higher than median of real data; $p$-value $=0.004)$. In final effluent from TF plants, the median concentrations of empirical and simulated data were significantly different (Mann Whitney test) for F-RNAPH (median of simulated data lower than median of real data; $\mathrm{p}$-value $=0.000$ ) and HAdv (median of simulated data higher than median of real data; $p$-value $=0.001$ ). For the other microorganisms, empirical and simulated median concentrations were not shown to be significantly different (Mann Whitney test; $p$-value $\geq 0.05$ ). In addition, in the three cases in which the median values for simulated and empirical data were shown to be significantly different, the proposed model was shown to over-estimate the reduction of F-RNAPH (AS and TF systems) and HAdv (TF systems), i.e., median concentrations in final effluents of simulated data were significantly lower than those derived from empirical data.

\subsection{Sensitivity analysis}

Figure 5 presents 'tornado graphs' with the results of the sensitivity analysis that was performed to identify which input variables of the proposed model $\left(C_{\text {raw }}=\right.$ microorganism concentration in raw wastewater; $\pi_{\text {prim }}=$ efficacy of preliminary and primary treatment; $\pi_{\mathrm{sec}}=$ efficacy of secondary treatment; $\Pi_{\text {tert }}=$ efficacy of tertiary treatment) had the greatest influence on the mean concentration of microorganisms estimated in the final effluent $\left(C_{\text {final }}\right)$. 'Tornado graphs' are useful as they present a ranking of the input distributions that impact a particular output: inputs with the largest impact on the distribution of the output have the longest (and uppermost) bars in the graph (PALISADE, 2013).

For phages, $\mathrm{C}_{\text {raw }}$ and $\pi_{\mathrm{sec}}$ were the two input variables that had the greatest impact on $\mathrm{C}_{\text {final }}$ in both AS and TF systems. Interestingly, for all three groups of phages, $C_{\text {raw }}$ was the input variable which had the greatest impact on $\mathrm{C}_{\text {final }}$ in TF systems, whereas in AS systems, it was $\pi_{\text {sec }}$ (Figure 5). Furthermore, with regard to the sensitivity analysis of phages, in general, it was observed that: the impacts of $\mathrm{C}_{\text {raw }}$ and $\Pi_{\mathrm{sec}}$ on $\mathrm{C}_{\text {final }}$ were similar to one another; the impacts of $\mathrm{C}_{\text {raw }}$ and $\Pi_{\mathrm{sec}}$ were considerably greater than the impacts of $\pi_{\text {prim }}$ and $\pi_{\text {tert }}$; and the impacts of $\pi_{\text {prim }}$ and $\pi_{\text {tert }}$ were also 
similar to one another. The only exception to this was F-RNAPH in TF systems, where the impact of $C_{\text {raw }}$ was considerably higher than the removal rates in all treatment steps $\left(\pi_{\text {prim }}, \Pi_{\text {sec }}\right.$ and $\left.\Pi_{\text {tert }}\right)$, with the impact of these three variables being similar to one another (Figure 5).

Conversely, for FIB, $\Pi_{\text {tert }}$ was also shown to have considerable impact on $\mathrm{C}_{\text {final. }}$ In TF systems, $\Pi_{\text {tert }}$ was observed to be the input variable with the greatest impact on $\mathrm{C}_{\text {final, }}$, followed by $\mathrm{C}_{\text {raw }}$ for $\mathrm{FC}$ and by $\pi_{s e c}$ for IE (Figure 5). For FC in AS plants, $\Pi_{s e c}$ was the input variable with the highest impact on

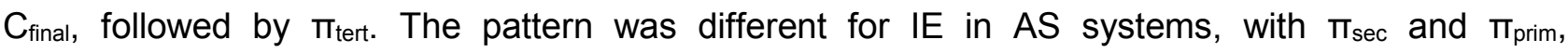
respectively, having the greatest and second highest impact on $\mathrm{C}_{\text {final. }}$ Interestingly, in this last case, $\mathrm{C}_{\text {raw }}$ had very little impact on $\mathrm{C}_{\text {final }}$ (Figure 5).

For HAdv in AS systems, $\Pi_{s e c}$ was the input variable with the greatest impact on $C_{\text {final }}$, followed by $C_{\text {raw }}$ and then $\pi_{\text {sec }}$ (Figure 5). Sensitivity analysis was not performed for $\pi_{\text {prim }}$ because a point estimate value equal to one was assumed for this variable due to the limited sample size. For HAdv in TF plants, the impact of $\mathrm{C}_{\text {raw }}$ was considerably greater than the removal rates in all treatment steps ( $\pi_{\text {prim }}, \Pi_{\text {sec }}$ and $\pi_{\text {tert }}$ ), the impact of these three variables on $C_{\text {final }}$ being similar to one another (Figure 5).

\section{DISCUSSION}

The results presented here demonstrate how stochastic modelling of pathogen and indicator data can be used to successfully estimate their concentrations in the final effluents of AS and TF systems, based on only the input values, therefore obviating the need for final effluent monitoring. Concentrations obtained from the stochastic simulations are given as PDF, and encompass uncertainties associated with the input variables of the model. Importantly, these PDF can be used to incorporate such uncertainties into QMRA models in risk assessment studies.

As previously mentioned, the QMRA approach has been applied by different researchers to evaluate human health risks associated with wastewater reuse (Soller et al., 2017; Soller, Eftim and Nappier, 2018). The QMRA approach has also been successfully used to support the formulation of regulations associated with drinking water quality (WHO, 2011; USEPA, 2012) and 
the reuse of wastewater in agriculture (NRMMC/EPHC/AHMC, 2006; WHO, 2006). However, it is important to highlight that the QMRA approach depends on reliable information with regard to the various components of the model, one point of major concern being the pathogen concentrations in the final treatment product (Medema et al., 2006), especially viral pathogens, as a consequence of their low levels and problems associated with the detection limit of enumeration methods. Alternatively, probability values, which can be generated using stochastic modelling, could be used to feed QMRA models (Haas, Rose and Gerba, 2014).

Stochastic modelling has been successfully applied in other related scientific fields (Baranyi, 2002; Poschet, 2003; Kutalik, Razaz and Baranyi, 2005; Ponciano et al., 2005), and recently it has been proposed as a way to estimate the removal coefficients of phages in AS and TF treatment systems (Dias, Ebdon and Taylor, 2015). The main advantage of using stochastic models over deterministic models is the incorporation of the variations (uncertainties) associated with empirical data into the model (Poschet, 2003). It is proposed here that the stochastic modelling approach followed in this study produces reliable information on the removal of microorganisms, including viral pathogens, during wastewater treatment and that this information can support integrated water and sanitation safety planning approaches to human health risk management (QMRA models) especially with regard to wastewater reuse.

However, it is worth mentioning that the input variables of the proposed model in this study may have some uncertainty associated with them (e.g., with regard to recovery rates and infectivity). Although recovery rate was considered for the enumeration of HAdv in this study (Dias, 2016; Dias, Ebdon and Taylor, 2018), and despite the fact that uncertainties are generally incorporated into stochastic modelling, uncertainties have to be specifically addressed when stochastic modelling is used to support risk assessment studies (e.g., decision support or legislation). This is especially true with regard to data on pathogens (e.g., HAdv), as uncertainties may have some impact on the estimated treatment product concentration, and consequently, on the risks calculated. In this context, sensitivity analysis offers a useful tool to indicate the main input variables of a given model that impact the output variable to the greatest extent (Zwieterin and van Gerwen, 2000). Such impact on the output is probably due to the uncertainties associated with the 
input variables. It is possible, therefore, to extract from this information which input variable (or variables) should be given more attention in order to further develop the model (Zwieterin and van Gerwen, 2000; Christopher Frey and Patil, 2002). According to (Medema et al., 2006), larger datasets can be used to reduce the uncertainties associated with a given input variable of the model.

From the results presented here, it is suggested that stochastic modelling may be used to estimate the microbial quality of final effluents of a wide variety of wastewater treatment processes and to verify whether they are likely to comply with discharge and/or reuse regulations. Therefore, the approach may support the safer discharge of treated wastewater into water bodies and/or its direct or indirect reuse for a variety of beneficial purposes including irrigation. Furthermore, this tool offers significant potential in aiding the design or selection of optimal wastewater treatment processes (or combination of processes) to ensure a final effluent quality that complies with national and international environmental guidelines and regulations.

\section{CONCLUSIONS}

The principal conclusions and outputs of this research may be summarised as follows:

- The proposed stochastic model appeared to estimate accurately the concentrations of all the studied microorganisms in the final effluents of both treatment systems. This is corroborated by the validation of the model, where median concentrations of empirical and simulated data were not statistically different for any microorganisms other than F-RNAPH in AS systems, and F-RNAPH and HAdv in TF systems.

- In general, the concentration in the raw wastewater $\left(\mathrm{C}_{\text {raw }}\right)$ and the efficacy of secondary treatment $\left(\pi_{\mathrm{sec}}\right)$ were shown to be the model input variables that had the greatest impact on the output $\left(\mathrm{C}_{\text {final }}\right)$. From this, it is envisaged that, appropriate attention given to specific variables of the model, reliable estimates of final concentrations of microorganisms in WWTP can be generated. 
- The stochastic modelling approach proposed in this study was shown to produce reliable information on the removal of microorganisms (including viral pathogens) during wastewater treatment that could support integrated water and sanitation safety planning approaches to human health risk management (QMRA models), especially with regards to wastewater reuse.

- This tool has significant potential to support the design and selection of optimal wastewater treatment processes (or combination of processes), to ensure a final effluent quality that complies with relevant environmental guidelines and regulations.

\section{ACKNOWLEDGEMENTS}

The authors would like to thank the Brazilian National Council for Scientific and Technological Development $(\mathrm{CNPq})$ for funding the $\mathrm{PhD}$ studies of Edgard Dias, and also Southern Water Services Ltd for its cooperation.

\section{REFERENCES}

Akhoundi, A. and Nazif, S. (2018) 'Sustainability assessment of wastewater reuse alternatives using the evidential reasoning approach', Journal of Cleaner Production, 195, pp. 1350-1376. doi: 10.1016/j.jclepro.2018.05.220.

Anderson, J. (2003) 'The environmental benefits of water recycling and reuse', Water Science and Technology: Water Supply, 3(4), pp. 1-10. doi: 10.2166/ws.2003.0041.

Aw, T. G. G. and Gin, K. Y.-H. Y. H. (2010) 'Environmental surveillance and molecular characterization of human enteric viruses in tropical urban wastewaters', Journal of Applied Microbiology, 109(2), pp. 716-730. doi: 10.1111/j.1365-2672.2010.04701.x.

Baranyi, J. (2002) 'Stochastic modelling of bacterial lag phase', International Journal of Food Microbiology, 73(2-3), pp. 203-206. doi: 10.1016/S0168-1605(01)00650-X.

Beaudequin, D. et al. (2015) 'Modelling microbial health risk of wastewater reuse: A systems perspective', Environment International, 84, pp. 131-141. doi: 10.1016/j.envint.2015.08.001.

Blokker, M., Smeets, P. and Medema, G. (2014) 'QMRA in the Drinking Water Distribution System', Procedia Engineering, 89, pp. 151-159. doi: 10.1016/j.proeng.2014.11.171.

BSI (2000) Water quality - Detection and enumeration of intestinal enterococci - Part 2: Membrane filtration method (ISO 7899-2:2000). London: British Standards Institute. 
BSI (2001a) Water quality - Detection and enumeration of bacteriophages - Part 2: Enumeration of somatic coliphages (ISO 10705-2:2001). London: British Standards Institute.

BSI (2001b) Water quality - Detection and enumeration of bacteriophages - Part 4: Enumeration of bacteriophages infecting Bacteroides fragilis (ISO 10705-4:2001). London: British Standard Institute.

BSI (2002) Water quality - Detection and enumeration of bacteriophages - Part 1: Enumeration of F-specific RNA bacteriophages (ISO 10705-1:2001). London: British Standards Institute.

BSI (2009) Water quality - Enumeration of Escherichia coli and coliform bacteria - Part 1: Membrane filtration method (ISO 9308-1:2000). London: British Standards Institute.

Carducci, A. et al. (2009) 'Viral Removal by Wastewater Treatment: Monitoring of Indicators and Pathogens', Food and Environmental Virology, 1(2), pp. 85-91. doi: 10.1007/s12560-009-9013-x.

Christopher Frey, H. and Patil, S. R. (2002) 'Identification and Review of Sensitivity Analysis Methods', Risk Analysis, 22(3), pp. 553-578. doi: 10.1111/0272-4332.00039.

Dias, E. H. O. (2016) Bacteriophages as surrogates of viral pathogens in wastewater treatment processes. Thesis (PhD), University of Brighton. Available at: https://core.ac.uk/download/pdf/42558148.pdf

Dias, E. H. O., Ebdon, J. and Taylor, H. (2015) 'The application of removal coefficients for viruses in different wastewater treatment processes calculated using stochastic modelling', Water Science \& Technology, 71(9), p. 1382. doi: 10.2166/wst.2015.086.

Dias, E. H. O., Ebdon, J. and Taylor, H. (2018) 'The application of bacteriophages as novel indicators of viral pathogens in wastewater treatment systems', Water Research, 129, pp. 172-179. doi: 10.1016/j.watres.2017.11.022.

Ebdon, J. E. et al. (2012) 'Phages of bacteroides (GB-124): A novel tool for viral waterborne disease control?', Environmental Science and Technology, 46(2), pp. 1163-1169. doi: 10.1021/es202874p.

Ebdon, J., Muniesa, M. and Taylor, H. (2007) 'The application of a recently isolated strain of Bacteroides (GB-124) to identify human sources of faecal pollution in a temperate river catchment', Water Research, 41(16), pp. 3683-3690. doi: 10.1016/j.watres.2006.12.020.

Eftim, S. E. et al. (2017) 'Occurrence of norovirus in raw sewage - A systematic literature review and metaanalysis', Water Research, 111, pp. 366-374. doi: 10.1016/j.watres.2017.01.017.

Eisenberg, J. N. S. et al. (2008) 'Microbial Risk Assessment Framework for Exposure to Amended Sludge Projects', Environmental Health Perspectives, 116(6), pp. 727-733. doi: 10.1289/ehp.10994.

Flannery, J. et al. (2012) 'Concentration of Norovirus during Wastewater Treatment and Its Impact on Oyster Contamination', Applied and Environmental Microbiology, 78(9), pp. 3400-3406. doi: 10.1128/AEM.0756911.

Fumian, T. M. et al. (2011) 'One year environmental surveillance of rotavirus specie A (RVA) genotypes in circulation after the introduction of the Rotarix ${ }^{\circledR}$ vaccine in Rio de Janeiro, Brazil', Water Research, 45(17), pp. 5755-5763. doi: https://doi.org/10.1016/j.watres.2011.08.039.

Gale, P. (2005) 'Land application of treated sewage sludge: quantifying pathogen risks from consumption of crops', Journal of Applied Microbiology, 98(2), pp. 380-396. doi: 10.1111/j.1365-2672.2004.02482.x.

Garcia, X. and Pargament, D. (2015) 'Reusing wastewater to cope with water scarcity: Economic, social and environmental considerations for decision-making', Resources, Conservation and Recycling, 101, pp. 154166. doi: 10.1016/j.resconrec.2015.05.015.

Gerba, C. P. et al. (2008) 'Exposure and risk assessment of Salmonella in recycled residuals', Water Science \& Technology, 57(7), p. 1061. doi: 10.2166/wst.2008.235.

Haas, C. N., Rose, J. B. and Gerba, C. P. (2014) Quantitative Microbial Risk Assessment. 2nd edn. New York: Wiley. ISBN: 978-1-118-91002-3. 
Haas, C. N. and Trussell, R. R. (1998) 'Frameworks for assessing reliability of multiple, independent barriers in potable water reuse', Water Science and Technology, 38(6). doi: 10.1016/S0273-1223(98)00561-7.

Hewitt, J. et al. (2011) 'Influence of wastewater treatment process and the population size on human virus profiles in wastewater', Water Research, 45(18), pp. 6267-6276. doi: 10.1016/j.watres.2011.09.029.

Hewitt, J. et al. (2013) 'Evaluation of human adenovirus and human polyomavirus as indicators of human sewage contamination in the aquatic environment', Water Research, 47(17), pp. 6750-6761. doi: 10.1016/j.watres.2013.09.001.

Kay, D. et al. (2008) 'Faecal indicator organism concentrations in sewage and treated effluents', Water Research, 42(1-2), pp. 442-454. doi: 10.1016/j.watres.2007.07.036.

Kuo, D. H.-W. et al. (2010) 'Assessment of human adenovirus removal in a full-scale membrane bioreactor treating municipal wastewater', Water Research, 44(5), pp. 1520-1530. doi: 10.1016/j.watres.2009.10.039.

Kutalik, Z., Razaz, M. and Baranyi, J. (2005) 'Connection between stochastic and deterministic modelling of microbial growth', Journal of Theoretical Biology, 232(2), pp. 285-299. doi: 10.1016/j.jtbi.2004.08.013.

De Luca, G. et al. (2013) 'Removal of indicator bacteriophages from municipal wastewater by a full-scale membrane bioreactor and a conventional activated sludge process: Implications to water reuse', Bioresource Technology, 129, pp. 526-531. doi: 10.1016/j.biortech.2012.11.113.

Malamis, S. et al. (2015) 'Can strict water reuse standards be the drive for the wider implementation of MBR technology?', Desalination and Water Treatment. Taylor \& Francis, 53(12), pp. 3303-3308. doi: 10.1080/19443994.2014.933613.

Medema, G. et al. (2006) Quantitative Microbial Risk Assessment in the Water Safety Plan. Final report on the EU MicroRisk Project. Brussels: European Commission. Available at: https://www.kwrwater.nl/wpcontent/uploads/2016/09/MICRORISK-FINAL-REPORT-Quantitative-microbial-risk-assessment-in-theWater-Safety-Plan.pdf

Morgan, M. G. and Henrion, M. (1990) Uncertainty: A Guide to Dealing with Uncertainty in Quantitative Risk and Policy Analysis. Cambridge: Cambridge University Press.

NRMMC/EPHC/AHMC (2006) Australian guidelines for water recycling: managing health and environmental risks (Phase 1). Camberra. Natural Resource Management Ministerial Council / Environment Protection and Heritage Council / Australian Health Ministers Conference. Available at: https://www.susana.org/_resources/documents/default/2-1533-waterrecyclingguidelines-02nov06.pdf

Olivieri, A. et al. (1999) 'Estimation of Pathogen Removal in an Advanced Water Treatment Facility Using Monto Carlo Simulation', Water Science and Technology, 40(4-5). doi: 10.1016/S0273-1223(99)00504-1.

PALISADE (2013) @RISK - Risk Analysis and Simulation Add-In for Microsoft $@$ Excel: User Guide. Ithaca: Palisade Corporation.

Parashar, U. D. et al. (2006) 'Rotavirus and Severe Childhood Diarrhea', Emerging Infectious Diseases, 12(2), pp. 304-306. doi: 10.3201/eid1202.050006.

Ponciano, J. M. et al. (2005) 'Use of Stochastic Models To Assess the Effect of Environmental Factors on Microbial Growth', Applied and Environmental Microbiology, 71(5), pp. 2355-2364. doi: 10.1128/AEM.71.5.2355-2364.2005.

Poschet, F. (2003) 'Monte Carlo analysis as a tool to incorporate variation on experimental data in predictive microbiology', Food Microbiology, 20(3), pp. 285-295. doi: 10.1016/S0740-0020(02)00156-9.

Purnell, S. et al. (2015) 'Bacteriophage removal in a full-scale membrane bioreactor (MBR) - Implications for wastewater reuse', Water Research, 73, pp. 109-117. doi: 10.1016/j.watres.2015.01.019.

Razzolini, M. T. P. et al. (2016) 'Giardia and Cryptosporidium infection risk by simultaneous exposure to drinking water', Microbial Risk Analysis, 4, pp. 1-6. doi: 10.1016/j.mran.2016.01.001. 
Sidhu, J. P. S., Ahmed, W. and Toze, S. (2013) 'Sensitive detection of human adenovirus from small volume of primary wastewater samples by quantitative PCR', Journal of Virological Methods, 187(2), pp. 395-400. doi: 10.1016/j.jviromet.2012.11.002.

Sima, L. C. et al. (2011) 'Calicivirus Removal in a Membrane Bioreactor Wastewater Treatment Plant', Applied and Environmental Microbiology, 77(15), pp. 5170-5177. doi: 10.1128/AEM.00583-11.

Smeets, P. W. M. H. (2011) Stochastic Modelling of Drinking Water Treatment in Quantitative Microbial Risk Assessment. 1st edn. London: IWA Publishing.

Soller, J. A. et al. (2017) 'Evaluation of microbiological risks associated with direct potable reuse', Microbial Risk Analysis, 5, pp. 3-14. doi: 10.1016/j.mran.2016.08.003.

Soller, J. A., Eftim, S. E. and Nappier, S. P. (2018) 'Direct potable reuse microbial risk assessment methodology: Sensitivity analysis and application to State log credit allocations', Water Research, 128, pp. 286-292. doi: 10.1016/j.watres.2017.10.034.

USEPA (2012) 2012 Edition of the Drinking Water Standards and Health Advisories (EPA 822-S-12-001). Washington, DC: United States Environmental Protection Agency.

USEPA (2015) Review of coliphages as possible indicators of fecal contamination for ambient water quality (EPA 820-R-15-098). Washington, DC: United States Environmental Protection Agency.

Victoria, M. et al. (2010) 'One year monitoring of norovirus in a sewage treatment plant in Rio de Janeiro, Brazil', Journal of Water and Health, 08(1), p. 158. doi: 10.2166/wh.2009.012.

Vijayavel, K. et al. (2010) 'Isolation and characterization of Bacteroides host strain HB-73 used to detect sewage specific phages in Hawaii', Water Research, 44(12), pp. 3714-3724. doi: 10.1016/j.watres.2010.04.012.

Vose, D. (2008) Risk Analysis: A Quantitative. 3rd edn. New York: Wiley.

Warsinger, D. M. et al. (2018) 'A review of polymeric membranes and processes for potable water reuse', Progress in Polymer Science, 81, pp. 209-237. doi: 10.1016/j.progpolymsci.2018.01.004.

WHO (2006) WHO guidelines for the safe use of wastewater, excreta and greywater. Geneva: World Health Organization.

WHO (2011) Guidelines for drinking water quality. 4th edn. Geneva: World Health Organization.

Wolf, S., Hewitt, J. and Greening, G. E. (2010) 'Viral Multiplex Quantitative PCR Assays for Tracking Sources of Fecal Contamination', Applied and Environmental Microbiology, 76(5), pp. 1388-1394. doi: 10.1128/AEM.02249-09.

Xue, B. et al. (2013) 'Effects of chlorine and chlorine dioxide on human rotavirus infectivity and genome stability’, Water Research, 47(10), pp. 3329-3338. doi: 10.1016/j.watres.2013.03.025.

Zwieterin, M. H. and van Gerwen, S. J. (2000) 'Sensitivity analysis in quantitative microbial risk assessment.', International journal of food microbiology, 58(3), pp. 213-21. 

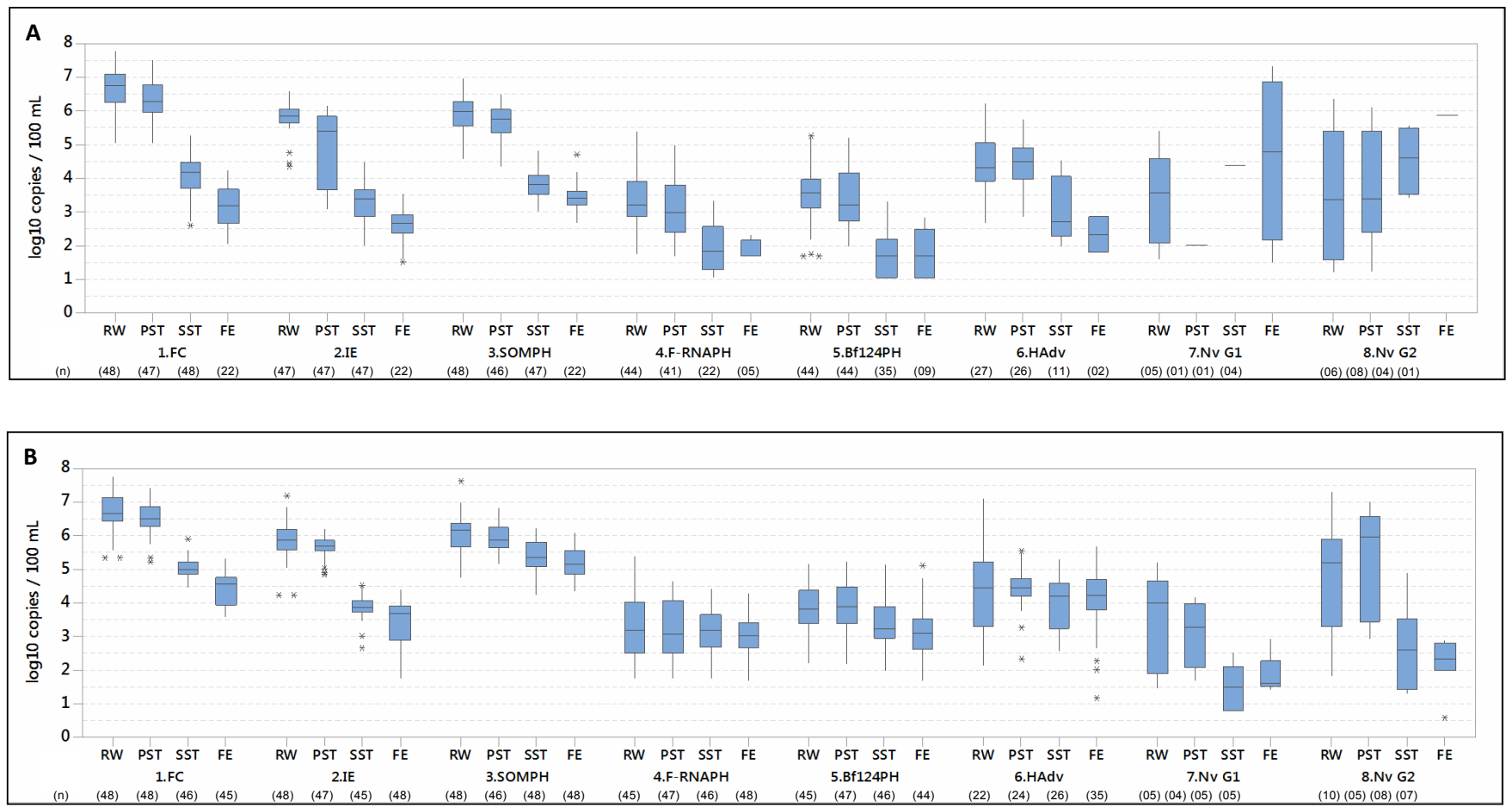

Figure 1 - Boxplot graphics of the concentrations of faecal coliforms (FC), intestinal enterococci (IE), somatic coliphages (SOMPH), F-RNA coliphages (F-RNAPH), B. fragilis phages (Bf124PH), human adenoviruses (HAdv), noroviruses genogroup 1 (Nv G1) and noroviruses genogroup 2 (Nv G2) at each treatment step in the activated sludge systems (A) and trickling filters (B). 
Boxplot graphic $=$ minimum value, $25^{\text {th }}$ percentile, median, $75^{\text {th }}$ percentile, maximum value and outliers $\left({ }^{*}\right.$ symbol $) ;(n)=$ sample size; $R \mathrm{~W}=$ raw wastewater; PST = primary sedimentation tank; SST = secondary sedimentation tank; FE = final effluent. 


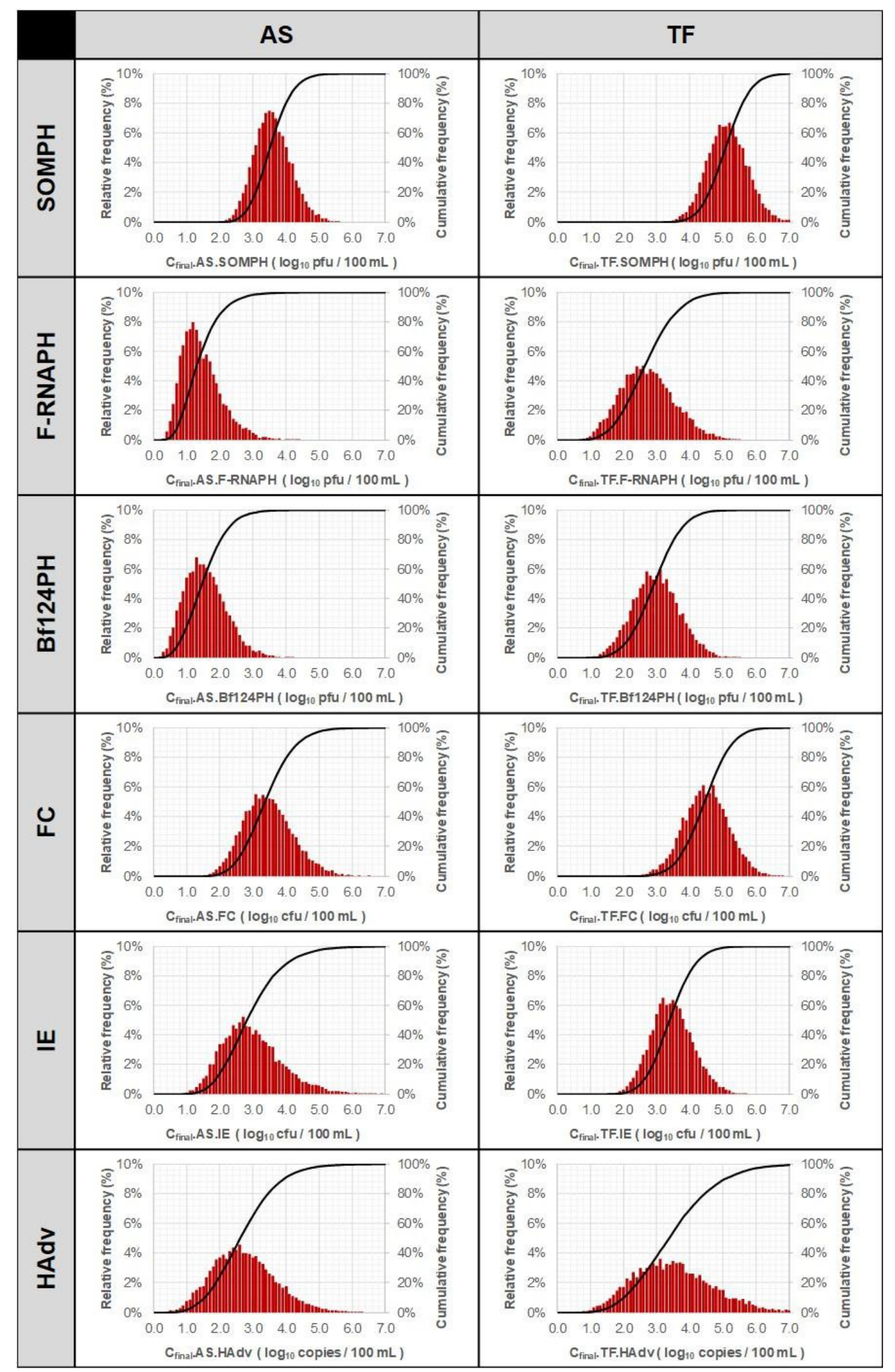

Figure 2 - Histogram and cumulative frequency curve of the estimated concentrations of microorganisms in the final effluents of AS and TF systems, calculated by the proposed model using stochastic simulations. 
SOMPH = somatic coliphages; F-RNAPH = F-RNA coliphages; $\mathrm{Bf124PH}=$ Bacteroides fragilis phages; FC = faecal coliforms; IE = intestinal enterococci; HAdv = human adenoviruses.
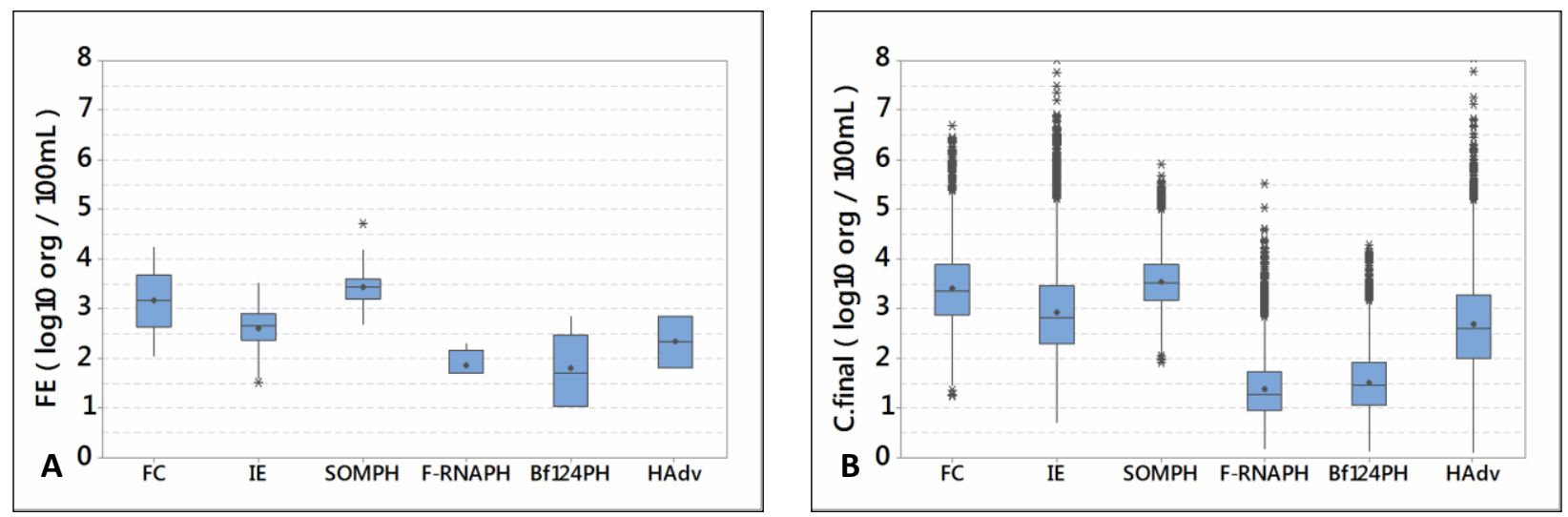

Figure 3 - Boxplot graphics of the concentrations of the microorganisms in the final effluent of AS systems observed from the WWTP monitoring programme (A) and estimated using stochastic modelling (B).

Boxplot graphic $=$ minimum value, 25 th percentile, median, mean $(\triangleleft$ symbol $)$ 75th percentile, maximum value and outliers ( ${ }^{*}$ symbol); $\mathrm{FE}=$ observed concentrations in final effluent; $\mathrm{C}_{\text {.final }}=$ estimated concentrations in final effluent; $F C=$ faecal coliforms; IE = intestinal enterococci; SOMPH = somatic coliphages; F-RNAPH = F-RNA coliphages; $\mathrm{Bf} 124 \mathrm{PH}=$ Bacteroides fragilis phages; HAdv = human adenoviruses. 

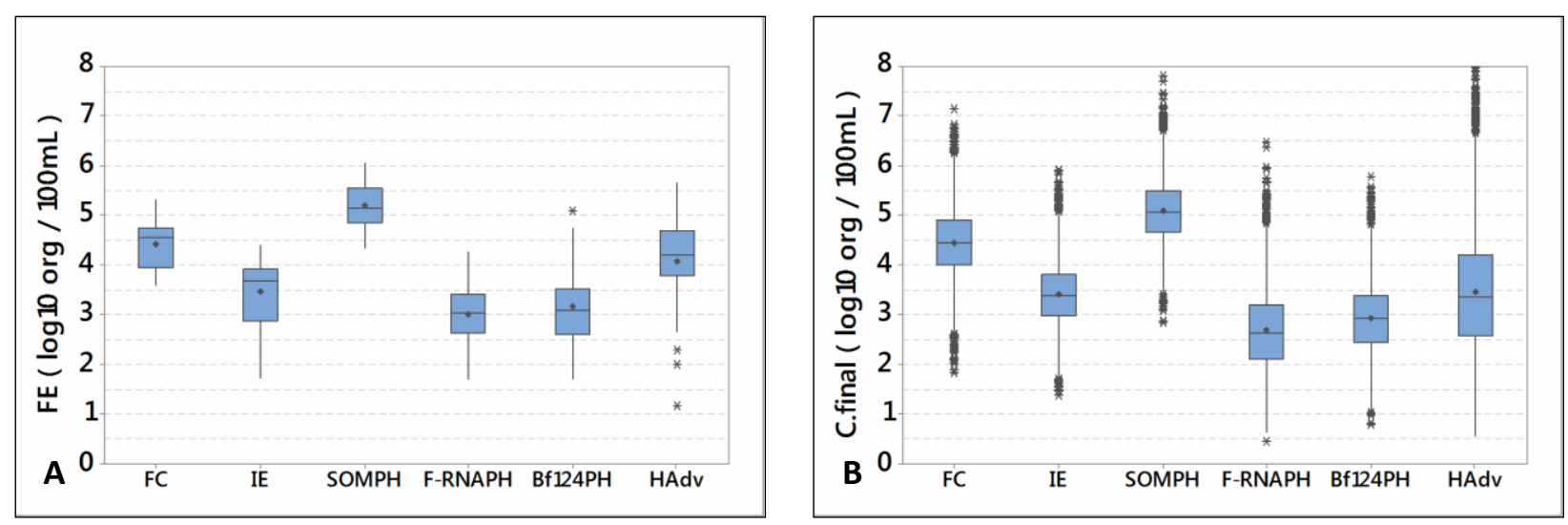

Figure 4 - Boxplot graphics of the concentrations of the microorganisms in the final effluent of TF systems observed from the WWTP monitoring programme (A) and estimated using stochastic modelling (B).

Boxplot graphic $=$ minimum value, 25 th percentile, median, mean $(\bullet$ symbol $)$ 75th percentile, maximum value and outliers ( ${ }^{*}$ symbol); $\mathrm{FE}=$ observed concentrations in final effluent; $\mathrm{C}_{\text {.final }}=$ estimated concentrations in final effluent; $\mathrm{FC}=$ faecal coliforms; IE = intestinal enterococci; SOMPH = somatic coliphages; F-RNAPH = F-RNA coliphages; $\mathrm{Bf124PH}=$ Bacteroides fragilis phages; HAdv = human adenoviruses. 


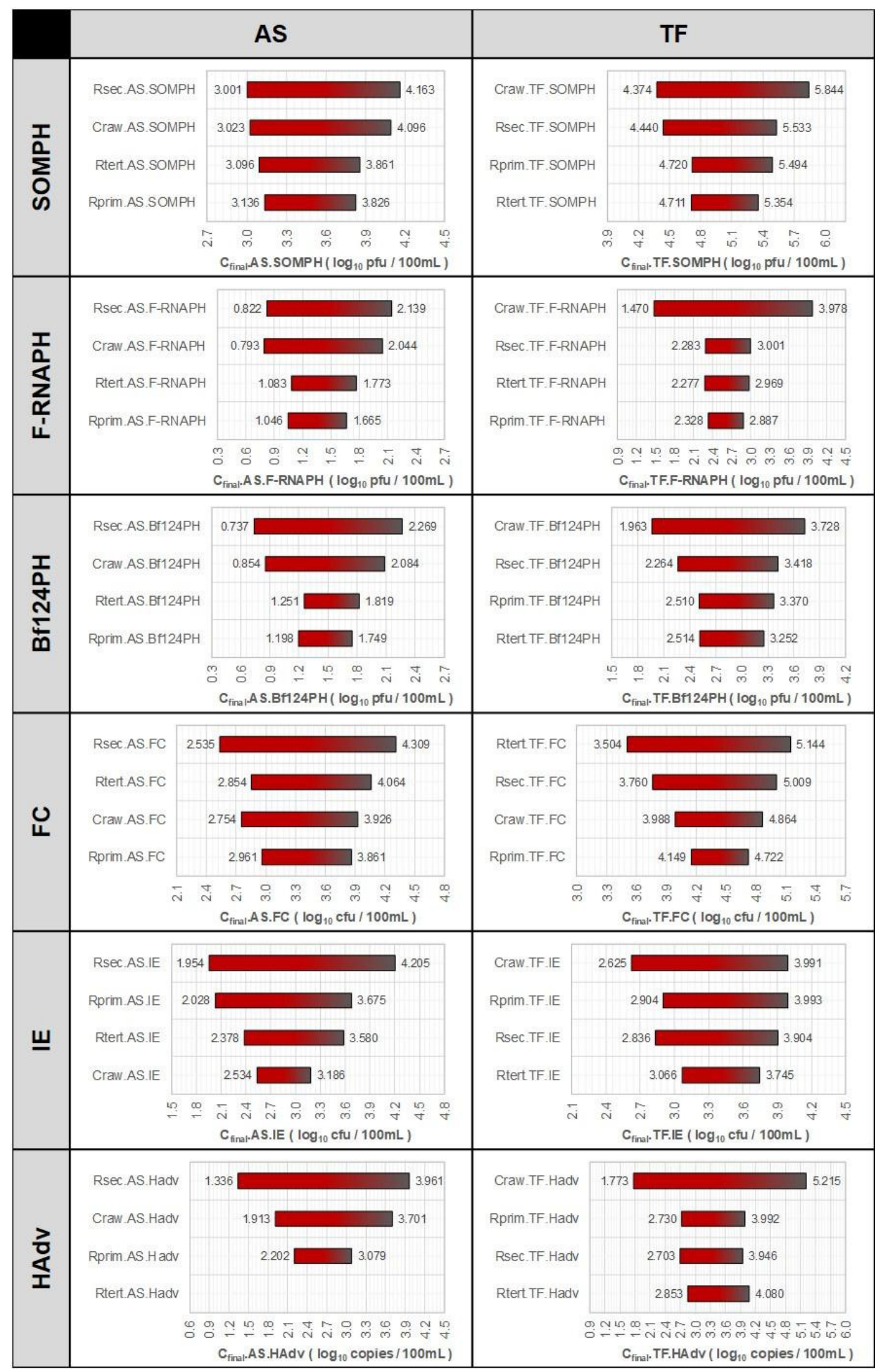

Figure 5 - 'Tornado graphs' to display the ranking of input variables for the proposed model that impact the output mean value.

SOMPH = somatic coliphages; F-RNAPH = F-RNA coliphages; $\mathrm{Bf} 124 \mathrm{PH}=$ Bacteroides fragilis phages; FC = faecal coliforms; IE = intestinal enterococci; HAdv = human adenoviruses. 
Table 1 - Probability distribution functions ${ }^{(a)}$ of the input variables of the proposed model ${ }^{(b)}$ to estimate the concentration of microorganisms in the final effluents of AS and TF systems.

\begin{tabular}{|c|c|c|c|}
\hline \multirow{2}{*}{ Org } & \multirow{2}{*}{ Input variable } & \multicolumn{2}{|c|}{ WWTP } \\
\hline & & AS & TF \\
\hline \multirow{4}{*}{ SOMPH ${ }^{(c)}$} & $C_{\text {raw }}$ & Gamma $(129,0.046)$ & Gamma (145.2,0.042) \\
\hline & $\pi_{\text {prim }}$ & Weibull $(22.44,0.964)$ & Gamma $(543.1,0.002)$ \\
\hline & $\pi_{\mathrm{sec}}$ & Log-N $(0.688,0.066)$ & Weibull $(19.93,0.934)$ \\
\hline & $\pi_{\text {tert }}$ & Weibull $(19.98,0.947)$ & Weibull $(33.69,0.973)$ \\
\hline \multirow{4}{*}{ F-RNAPH ${ }^{(c)}$} & $\mathrm{C}_{\text {raw }}$ & Beta $(8.833,12.729)$ & Beta $(7.981,12.455)$ \\
\hline & "prim & Weibull $(9.786,0.921)$ & Weibull $(19.18,0.977)$ \\
\hline & $\pi_{\mathrm{sec}}$ & Gamma $(13.99,0.040)$ & Weibull $(16.55,0.961)$ \\
\hline & $\pi_{\text {tert }}$ & Log-N $(0.861,0.127)$ & Weibull $(16.32,0.968)$ \\
\hline \multirow{4}{*}{ Bf124PH ${ }^{\text {(c) }}$} & $\mathrm{C}_{\text {raw }}$ & Weibull $(4.918,3.838)$ & Beta $(10.194,5.081)$ \\
\hline & "prim & Weibull $(11.18,0.949)$ & Gamma $(151.5,0.006)$ \\
\hline & $\boldsymbol{\pi}_{\mathrm{sec}}$ & Beta $(4.750,3.689)$ & Weibull $(10.48,0.904)$ \\
\hline & $\pi_{\text {tert }}$ & Log-N $(0.937,0.097)$ & Weibull $(16.96,0.963)$ \\
\hline \multirow{4}{*}{$F C^{(d)}$} & $C_{\text {raw }}$ & Weibull $(12.543,6.907)$ & Beta $(34.015,10.388)$ \\
\hline & $\boldsymbol{\pi}_{\text {prim }}$ & Gamma $(179.0,8,0.005)$ & Gamma $(732.8,0.001)$ \\
\hline & $\pi_{\mathrm{sec}}$ & Beta $(23.767,26.008)$ & Log-N $(0.7756,0.045)$ \\
\hline & $\pi_{\text {tert }}$ & Gamma $(99.933,0.008)$ & Weibull $(11.31,0.927)$ \\
\hline \multirow{4}{*}{$\mathrm{IE}^{\text {(d) }}$} & $C_{\text {raw }}$ & Weibull $(18.39,5.967)$ & Beta $(32.041,12.639)$ \\
\hline & $\pi_{\text {prim }}$ & Weibull $(7.439,0.909)$ & Gamma $(307.5,0.003)$ \\
\hline & $\pi_{\mathrm{sec}}$ & Log-N $(0.689,0.154)$ & Log-N $(0.690,0.062)$ \\
\hline & $\pi_{\text {tert }}$ & Gamma $(71.66,0.012)$ & Weibull $(10.39,0.933)$ \\
\hline \multirow{4}{*}{ HAdv (e) } & $\mathrm{C}_{\text {raw }}$ & Log-N $(4.526,0.859)$ & Beta $(6.3999,8.559)$ \\
\hline & $\pi_{\text {prim }}$ & Weibull $(13.50,0.962)$ & Weibull $(10.76,0.962)$ \\
\hline & $\pi_{\mathrm{sec}}$ & Weibull $(3.991,0.710)$ & Weibull $(11.60,0.942)$ \\
\hline & $\pi_{\text {tert }}$ & Point estimate value (1.000) & Gamma $(99.02,0.010)$ \\
\hline
\end{tabular}

\footnotetext{
${ }^{(a)}$ Point estimate value (1.000); Log-N $(\mu \sigma)=$ log-normal distribution with mean $\mu$ and standard deviation $\sigma$; Weilbull $(\alpha, \beta)=$ Weibull distribution with shape parameter $\alpha$ and scale parameter $\beta$; Beta $(\alpha ; \beta)=$ Beta distribution with two shape parameters $\alpha$ and $\beta$; Gamma $(\alpha, \beta)=$ Gamma distribution with shape parameter $\alpha$ and scale parameter $\beta$.

${ }^{(b)} ; C_{\text {final }}=$ microorganism concentration in final effluent; $C_{\text {in }}=$ microorganism concentration in raw wastewater; $\Pi_{\text {prim }}=$ efficacy of preliminary and primary treatment; $\Pi_{s e c}$ = efficacy of secondary treatment; $\Pi_{\text {tert }}=$ efficacy of tertiary treatment;

(c) $\log _{10}$ (pfu. $100 \mathrm{~mL}^{-1}$ ); (d) $\log _{10}\left(\mathrm{cfu} .100 \mathrm{~mL}^{-1}\right.$ ); (e) $\log _{10}$ (copies. $100 \mathrm{~mL}^{-1}$ ).

AS = activated sludge systems; TF = trickling filter systems; SOMPH = somatic coliphages; F-RNAPH = FRNA coliphages; $\mathrm{Bf} 124 \mathrm{PH}=$ Bacteroides fragilis phages; $\mathrm{FC}=$ faecal coliforms; IE = intestinal enterococci; HAdv = human adenoviruses.
} 
Table 2 - Summary of the statistics for the estimate concentration ${ }^{(a)}$ of microorganisms in the final effluents of trickling filter and activated sludge systems.

\begin{tabular}{|c|c|c|c|c|c|c|c|}
\hline \multirow[t]{2}{*}{ System } & \multirow{2}{*}{ Parameter } & \multicolumn{2}{|c|}{ (b) } & \multicolumn{2}{|c|}{ Microorganism } & \multirow{2}{*}{ (c) } & \multirow{2}{*}{ HAdv } \\
\hline & & SOMPH & F-RNAPH & Bf124PH(b) & $F^{(c)}$ & & \\
\hline \multirow{7}{*}{ AS } & Median & 3.51 & 1.29 & 1.46 & 3.36 & 2.82 & 2.61 \\
\hline & Mean & 3.55 & 1.40 & 1.52 & 3.41 & 2.93 & 2.69 \\
\hline & SD & 0.55 & 0.60 & 0.62 & 0.74 & 0.91 & 0.96 \\
\hline & Low $95 \% \mathrm{Cl}$ & 2.48 & 0.22 & 0.30 & 1.95 & 1.15 & 0.82 \\
\hline & High $95 \% \mathrm{Cl}$ & 4.62 & 2.58 & 2.74 & 4.87 & 4.71 & 4.57 \\
\hline & Kurtosis & 3.03 & 4.79 & 3.36 & 3.22 & 4.13 & 3.72 \\
\hline & Skewness & 0.29 & 1.05 & 0.58 & 0.41 & 0.78 & 0.56 \\
\hline \multirow{7}{*}{ TF } & Median & 5.07 & 2.63 & 2.92 & 4.44 & 3.39 & 3.37 \\
\hline & Mean & 5.09 & 2.68 & 2.94 & 4.44 & 3.41 & 3.46 \\
\hline & SD & 0.60 & 0.80 & 0.69 & 0.67 & 0.63 & 1.20 \\
\hline & Low $95 \% \mathrm{Cl}$ & 3.91 & 1.11 & 1.57 & 3.12 & 2.18 & 1.12 \\
\hline & High $95 \% \mathrm{Cl}$ & 6.27 & 4.25 & 4.30 & 5.76 & 4.64 & 5.81 \\
\hline & Kurtosis & 3.09 & 3.00 & 2.98 & 3.02 & 3.02 & 3.20 \\
\hline & Skewness & 0.15 & 0.35 & 0.16 & 0.00 & 0.22 & 0.49 \\
\hline
\end{tabular}

\footnotetext{
(a) estimate concentration of microorganisms in the final effluents of AS and TF systems calculated using stochastic simulations and the proposed model ; $\mathrm{C}_{\text {final }}=$ microorganism concentration in final effluent; $\mathrm{C}_{\text {raw }}=$ microorganism concentration in raw wastewater; $\pi_{\text {prim }}=$ efficacy of preliminary and primary treatment; $\pi_{\mathrm{sec}}=$ efficacy of secondary treatment; $\Pi_{\text {tert }}=$ efficacy of tertiary treatment;

(b) $\log _{10}$ (pfu. $100 \mathrm{~mL}^{-1}$ ); (c) $\log _{10}\left(\mathrm{cfu} .100 \mathrm{~mL}^{-1}\right.$ ); (d) $\log _{10}$ (copies. $100 \mathrm{~mL}^{-1}$ ).

AS = activated sludge systems; TF = trickling filter systems; SOMPH = somatic coliphages; F-RNAPH = FRNA coliphages; Bf124PH = Bacteroides fragilis phages; FC = faecal coliforms; IE = intestinal enterococci; HAdv = human adenoviruses; SD = standard deviation; Low 95\% IC = lower 95\% confidence interval; High $95 \%$ IC = higher $95 \%$ confidence interval.
} 